\title{
Efisiensi Pupuk dan Peningkatan Hasil Padi Gogo dengan Aplikasi Pupuk Hayati dan Arang Tempurung Kelapa
}

\author{
Betty Natalie Fitriatin'1), Tien Turmuktini2), Muhamad Iqbal Kusma Sudana2, \\ Dzakaria Yogaswara 2), dan Randy Nugraha2) \\ 1)Departemen Ilmu Tanah dan Sumberdaya Lahan, Fakultas Pertanian Universitas Padjadjaran \\ Jl. Raya Bandung Sumedang Km 21 Jatinangor \\ 2)Fakultas Pertanian Universitas Winayamukti \\ Jl. Bandung-Sumedang No.29, Gunungmanik, Kec. Tanjungsari, Kab. Sumedang \\ Korespondensi: betty.natalie@unpad.ac.id
}

\begin{abstract}
The intensive application of inorganic fertilizers has a negative impact on soil health. Furthermore, the price of inorganic fertilizers has increased hence the production costs will also increase. Efforts to improve fertilizer efficiency and encourage environmentally friendly crops can be done by application of biofertilizers and organic ameliorants. The field experiment has been carried out to study the effect of biofertilizers application and coconut shell charcoal to increase inorganic fertilizers efficiency and yield of upland rice at Rancakalong, Sumedang, West Java. The experiment used factorial randomized block design consisted two factors. The first factor were biofertilizers and coconut shell charcoal and the second factors were inorganic fertilizers doses. Biofertilizers with consortia of Azotobacter chroococum, Azospirillum sp., Pseudomonas mallei, Burkolderia sp., Aspergillus niger, and Penicillium sp. and organic ameliorant was coconut shell charcoal. NPK fertilizers were applied in 25\%,50\%, 75\% and 100\% of recommended doses. The results revealed that biofertilizers and coconut shell charcoal increased growth and yield of upland rice. This finding concludes that application of biofertilizers and coconut shell charcoal reduced the dose of inorganic fertilizers up to $25 \%$.
\end{abstract}

Keywords: ameliorant, biofertilizers, efficiency, inorganic and upland rice

\section{PENDAHULUAN}

Kebutuhan padi sebagai salah satu sumber pangan utama masyarakat Indonesia akan terus meningkat, hal ini dikarenakan jumlah penduduk terus bertambah. Indonesia dengan jumlah penduduk yang sangat besar menghadapi tantangan dalam memenuhi kebutuhan pangan, oleh karena itu, kebijakan ketahanan pangan menjadi fokus utama dalam pembangunan pertanian. Di sisi lain, luas lahan untuk pemenuhan kebutuhan pangan terutama lahan sawah semakin berkurang.

Salah satu upaya yang dapat dilakukan untuk pemenuhan kebutuhan pangan terutama padi adalah dengan pemanfaatan lahan kering. Lahan kering berupa tegalan belum dimanfaatkan secara optimal untuk tanaman pangan. Budidaya padi di lahan kering atau padi gogo merupakan salah satu solusi untuk menambah pemenuhan kebutuhan padi nasional. Namun demikian, terdapat kendala yang sering menjadi faktor pembatas usaha tani di lahan kering yaitu rendahnya tingkat kesuburan tanah yang disebabkan kemasaman tanah, kandungan unsur hara makro dan bahan organik yang rendah.

Pemupukan dengan pupuk anorganik yang terus menerus pada budidaya padi gogo dapat berdampak buruk pada kesehatan tanah. Pemanfaatan pupuk hayati yang mengandung mikroba menguntungkan dalam memfasilitasi ketersediaan hara makro merupakan solusi untuk meningkatkan kandungan hara tanah dan tidak berdampak buruk terhadap kesehatan tanah. Selain itu, untuk mengoptimalkan kinerja pupuk hayati dan meningkatkan kandungan bahan organik tanah, dapat dilakukan dengan penambahan amelioran organik.

Pupuk hayati merupakan bahan yang mengandung mikroba bermanfaat untuk meningkatkan ketersediaaan unsur hara tanah dan memacu pertumbuhan tanaman. Pupuk hayati dinilai mempunyai prospek yang bagus 
dalam pengembangan pertanian berkelanjutan (Macik et. al., 2020). Mikroba bermanfat yang digunakan sebagai pupuk hayati diantaranya: bakteri penambat nitrogen, mikroorganisme pelarut fosfat, mikoriza, dan bakteri penghasil fitohormon (Chaudhary et. al., 2019). Peranan pupuk hayati untuk meningkatkan kandungan hara tanah serta produksi tanaman telah banyak diteliti. Wahane et. al. (2020) menjelaskan lebih luas kelebihan pupuk hayati yaitu mengurangi penggunaan pupuk kimia dan polusi lingkungan, meningkatkan ketersedian hara dan mampu memacu pertumbuhan tanaman serta dapat memperbaiki sifat fisik, kimia dan biologi tanah.

Salah satu limbah pertanian yang dapat dijadikan bahan amelioran yaitu arang tempurung kelapa (Sulistyani et. al., 2015). Arang tempurung kelapa sangat bermanfaat sebagai amelioran organik karena mengandung unsur hara fosfor, kalium, natrium, magnesium dan unsur hara lainya. Unsur kalium pada arang tempurung kelapa memiliki komposisi 45,01 \% yang dapat digunakan sebagai pengganti unsur kalium dari pupuk anorganik (Sudding dan Jamaluddin, 2016). Aplikasi arang tem-purung kelapa mampu meningkatkan kapasi-tas tukar kation, $\mathrm{C}$ organik tanah dan hasil padi sawah (Herlambang et. al., 2020).

Pemafaatan arang tempurung kelapa diharapkan mampu memacu aktivitas mikroba dalam pupuk haya-ti sehingga peranan pupuk hayati lebih optimal. Untuk mengetahui lebih lanjut peranan pupuk hayati dan arang tempurung kelapa terhadap efisiensi pupuk NPK perlu dilakukan. Tujuan percobaan ini yaitu mempelajari peranan pupuk hayati konsorsium dan arang tempurung kelapa yang mengandung bakteri pemfiksasi $\mathrm{N}$ dan pelarut $\mathrm{P}$ untuk meningkatkan efisiensi pemupukan dan hasil padi gogo.

\section{METODOLOGI}

Percobaan dilaksanakan di kebun petani Desa Pasir Talang Kecamatan Rancakalong Kabupaten Sumedang, dengan ketinggian 894 meter di atas permukaan laut. Penelitian dilakukan pada bulan Agustus sampai November 2019.

Bahan-bahan yang digunakan di antaranya: arang tempurung kelapa, pupuk hayati, pupuk NPK, dan benih padi. Pupuk hayati yang digunakan merupakan konsorsium antara bakteri pemfik-sasi N yaitu Azotobacter dan chroococum Azospirillum sp. dengan mikroba pelarut fosfat (Pseudomonas mallei, Burkolderia sp., Aspergillus niger and Penicillium sp.). Bakteri yang digunakan merupakan isolat unggul hasil seleksi di Laboratorium Biologi Tanah Fakultas Pertanian Universitas Padjadjaran. Pupuk NPK yang digunakan terdiri atas: urea $(46 \% \mathrm{~N})$, SP$36\left(36 \% \mathrm{P}_{2} \mathrm{O}_{5}\right)$ dan $\mathrm{KCl}\left(60 \% \mathrm{~K}_{2} \mathrm{O}\right)$. Benih padi gogo yang digunakan adalah varietas Luhur 2 yang diperoleh dari Balai Besar Penelitian Tanaman Padi (BBPadi) Subang.

Rancangan percobaan menggunakan Racangan Acak Kelompok (RAK) pola faktorial yang terdiri dari dua faktor dengan tiga ulangan. Faktor pertama yaitu pupuk hayati dan arang tempurung kelapa yang terdiri atas 4 (empat) perlakuan, yaitu:

$$
\begin{aligned}
\mathrm{f}_{0}= & \text { tanpa perlakuan } \\
\mathrm{f}_{1}= & \text { pupuk hayati }\left(50 \mathrm{~kg} \mathrm{ha}^{-1}\right) \\
\mathrm{f}_{2}= & \text { arang tempurung kelapa } \left.4 \mathrm{tha}^{-1}\right) \\
\mathrm{f}_{3}= & \text { pupuk hayati }+ \text { arang tempurung } \\
& \text { kelapa. }
\end{aligned}
$$

Faktor kedua yaitu dosis pupuk N, P dan K, yang terdiri atas: $d_{0}=$ tanpa pupuk; $d_{1}=25 \%$; $d_{2}=50 \% ; d_{3}=75 \% ; d_{4}=100 \%$. Presentase dosis dihitung dari dosis rekomen-dasi pemupukan untuk padi gogo, yaitu: urea 300 kg ha-1, SP-36 $100 \mathrm{~kg} \mathrm{ha}^{-1}$ dan KCl $100 \mathrm{~kg} \mathrm{ha}^{-1}$.

Aplikasi pupuk hayati dan arang tempurung kelapa dilakukan pada 2 (dua) hari sebelum tanam (HST). Pemberian perlakuan pupuk NPK (sesuai dosis) diberikan pada waktu yang berbeda untuk setiap pupuk. Pupuk urea diberikan pada 2, 4 dan 6 minggu setelah tanam (MST), sementara pupuk SP-36 dan $\mathrm{KCl}$ diaplikasikan pada saat tanam.

Penanaman padi gogo menggunakan jarak tanam $20 \times 20 \mathrm{~cm}$. Pengamatan terhadap pertumbuhan (tinggi tanaman) dilakukan pada 
20, 30, 40, 50 dan 60 (HST), sedangkan pengamatan terhadap hasil (bobot gabah) pada fase generatif akhir atau setelah panen.

\section{HASIL DAN PEMBAHASAN}

\subsection{Karakteristik Tanah Sebelum Percobaan}

Hasil analisis tanah sebelum percobaan menunjukkan bahwa tekstur tanah yang digunakan sebagai media percobaan yaitu lempung berdebu. Nilai $\mathrm{pH}$ tanah sebesar 5,8 dan tergolong kriteria agak masam. Pertumbuhan padi gogo yang baik membutuhkan $\mathrm{pH}$ berkisar 5,58,0. Tanah ini memiliki kandungan C-organik sedang $(2,78 \%)$ dan kandungan N-total sebesar 0,12\% tergolong sedang. Kapasitas tukar kation (KTK) tanah sebesar 27,05 $\mathrm{cmol} \mathrm{g}$ 1 termasuk kriteria sedang.

Hasil analisis terhadap kandungan unsur $\mathrm{P}$ tanah yaitu kandungan $\mathrm{P}_{2} \mathrm{O}_{5}$ potensial 169,34 mg $100 \mathrm{~g}^{-1}$, yang tergolong sedang sedangkan kandungan $\mathrm{P}_{2} \mathrm{O}_{5}$ tersedia (metode Bray 1) sebesar $173,4 \mathrm{mg} 100 \mathrm{~g}^{-1}$, dan $\mathrm{K}_{2} \mathrm{O} 54,99 \mathrm{mg}$ $100 \mathrm{~g}^{-1}$ yang termasuk kriteria rendah. Nilai Ppotensial yang tergolong sedang, namun $\mathrm{P}$ tersedia yang tergolong rendah menujukkan adanya fiksasi P di dalam tanah.

Berdasarkan hasil analisis kandungan Corganik tanah yang sedang dan kandungan hara makro yang rendah maka tingkat kesuburan tanah ini tergolong rendah. Untuk mendukung pertumbuhan tanaman maka diperlukan penambahan amelioran organik serta upaya peningkatan kandungan C-organik tanah. Aplikasi pupuk hayati berupa konsorsium bakteri pemfiksasi $\mathrm{N}$ dan mikroba pelarut P diharapkan meningkatkan ketersediaan hara tanah. Berdasarkan hasil penelitian Fitriatin et. al. (2019), aplikasi konsorsium bakteri pemfiksasi $\mathrm{N}$ dan mikroba pelarut $\mathrm{P}$ meningkatkan kandungan $\mathrm{N}$ dan $\mathrm{P}$ pada tanah Ultisols.

\subsection{Pertumbuhan dan Hasil Padi Gogo}

Hasil pengamatan terhadap tinggi tanaman padi gogo menunjukkan tidak terjadi interaksi antara perlakuan pupuk hayati dan arang tempurung kelapa dengan pupuk anorganik (Tabel 1). Hasil percobaan menunjukkan perlakuan pupuk hayati dan arang tempurung kelapa tidak mampu meningkatkan tinggi tanaman secara signifikan. Hasil berbeda ditunjukkan oleh Wasis et al. (2018), bahwa pemberian arang tempurung kelapa meningkatkan secara signifikan tinggi tanaman dan berat kering Agathis dammara. Namun, secara umum pengamatan pada umur 20-60 HST perlakuan pupuk hayati dan arang tempurung kelapa berpotensi meningkatkan tinggi tanaman padi gogo.

Tabel 1 Tinggi tanaman padi gogo pada 20 HST, 30 HST, 40 HST, 50 HST, 60 HST yang dipengaruhi oleh pupuk hayati dan arang TK (tempurung kelapa)

\begin{tabular}{lccccc}
\hline \multirow{2}{*}{ Perlakuan } & \multicolumn{5}{c}{ Tinggi Tanaman $(\mathrm{cm})$} \\
\cline { 2 - 6 } Pupuk Hayati & 20 HST & 30 HST & 40 HST & 50 HST & 60 HST \\
- kontrol & 18,37 & 26,59 & 40,60 & 50,60 & 60,22 \\
- Pupuk hayati & 18,57 & 29,47 & 42.31 & 51,89 & 63,23 \\
- Arang TK & 18,50 & 30,30 & 42,49 & 52,32 & 63,73 \\
- Ppk hayati+Arang TK & 18,59 & 30,37 & 42,92 & 52,71 & 64,68 \\
\hline Pupuk N, P, K & & & & & \\
- $0 \%$ & 15,74 & 25,23 & 40,77 & 46,73 & 62,30 \\
- 25\% & 18,10 & 29,13 & 40.43 & 48,03 & 62,39 \\
- 50\% & 19,28 & 30,27 & 42,82 & 48,80 & 65,23 \\
- $75 \%$ & 20,16 & 30,59 & 44,89 & 52,82 & 65,57 \\
- $100 \%$ & 19,26 & 30,70 & 42,68 & 50,53 & 64,41 \\
\hline
\end{tabular}


Aplikasi pupuk hayati dan arang tempurung kelapa meningkatkan secara sinifikan jumlah anakan produktif (Tabel 2). Pupuk hayati yang mengandung bakteri pemfiksasi $\mathrm{N}$ dan mikroba perlarut $\mathrm{P}$ dinilai mampu meningkatkan pertumbuhan padi dalam hal ini jumlah anakan produtif padi gogo. Berdasarkan data pada Tabel 2, pemberian dosis pupuk N, P, K $75 \%$ rekomendasi dengan aplikasi pupuk hayati dan arang tempurung kelapa memberikan jumlah anakan yang lebih tinggi jika dibandingkan dengan kombinasi dosis lainnya. Hal ini menunjukkan bahwa pupuk hayati dan arang tempurung kelapa mampu mengurangi dosis pupuk N, P, K sebanyak 25\%. Hasil ini sejalan dengan hasil penelitian Khan (2018) dimana pupuk hayati dapat meningkatkan jumlah anakan produktif, bobot gabah dan bobot 1000 butir padi serta mengurangi kebutuhan pupuk N sebanyak $25 \%$.

Tabel 2 Jumlah anakan produktif yang dipengaruhi oleh pupuk hayati dan arang tempurung kelapa (TK)

\begin{tabular}{lc}
\hline \multicolumn{1}{c}{ Perlakuan } & $\begin{array}{c}\text { Jumlah Anakan } \\
\text { Produktif }\end{array}$ \\
\hline $\begin{array}{l}\text { Pupuk Hayati } \\
\text { - kontrol }\end{array}$ & $21,84 \mathrm{a}$ \\
- Pupuk hayati & $23,84 \mathrm{~b}$ \\
- Arang TK & $22,84 \mathrm{ab}$ \\
- Pupuk hayati+Arang TK & $24,16 \mathrm{~b}$ \\
\hline Pupuk N,P,K & \\
- $0 \%$ & $22,75 \mathrm{a}$ \\
- $25 \%$ & $22,75 \mathrm{a}$ \\
- $50 \%$ & $22,60 \mathrm{a}$ \\
- $75 \%$ & $22,90 \mathrm{a}$ \\
- $100 \%$ & $23,85 \mathrm{a}$ \\
\hline Keterangan: Angka rata-rata yang diikuti huruf sama \\
pada setiap kolom yang sama, menunjuk- \\
kan berbeda tidak nyata berdasarkan uji \\
jarak berganda Duncan pada taraf nyata \\
95\%.
\end{tabular}

Kombinasi perlakuan pupuk hayati dan arang tempurung kelapa lebih baik efeknya terhadap jumlah anakan produktif dibandingkan perlakuan pupuk hayati atau arang tempurung kelapa secara mandiri (Tabel 2). Peningkatan jumlah anakan produktif karema perlakuan gabungan pupuk hayati dengan arang tempurung kelapa mencapai 11\% dibandingkan degan kontrol. Hal ini membuktikan bahwa pupuk hayati lebih efektif perannya dalam memacu pertumbuhan tanaman apabila dikombinasikan dengan amelioran organik. Arang tempurung kelapa menjadi sumber karbon dan energi bagi mikroba dalam pupuk hayati. Hal ini didukung oleh hasil penelitian oleh Husna et. al. (2019) yang menunjukkan viabilitas mikroorganisme pelarut fosfat tertinggi pada bahan pembawa (carrier) biochar tempurung kelapa dibandingkan dengan biochar dari jerami padi, tongkol jagung, dan tandan kosong kelapa sawit.

Hasil percobaan menunjukkan perlakuan pupuk hayati dan arang tempurung kelapa tidak berinteraksi dengan perlakuan dosis pupuk N,P dam K terhadap hasil padi gogo, Bobot gabah kering giling yang dipengaruhi oleh pupuk hayati dan arang tempurung kelapa berkisar 5,5 - 7,2 tha-1 (Tabel 3).

Tabel 3 Bobot Gabah Kering Giling padi gogo yang dipengaruhi oleh pupuk hayati dan arang TK (tempurung kelapa)

\begin{tabular}{lcc}
\hline \multicolumn{1}{c}{ Perlakuan } & $\begin{array}{c}\text { Per } \\
\text { Rumpun } \\
(\mathrm{g})\end{array}$ & $\begin{array}{c}\text { Per } \\
\text { hektar } \\
\left(\mathrm{t} \mathrm{ha}^{-1}\right)\end{array}$ \\
\hline Pupuk Hayati & & \\
- Kontrol & 42,99 & 5,5 \\
- Pupuk hayati & 44,51 & 5,7 \\
- Arang TK & 45,64 & 6,4 \\
- Pupuk hayati + Arang & 47,80 & 7,2 \\
$\quad$ TK & & \\
\hline Pupuk N, P, K & & \\
- 0\% & 43,85 & 5,4 \\
- 25\% & 44,62 & 5,8 \\
- 50\% & 45,18 & 6,1 \\
- 75\% & 46,47 & 6,9 \\
- 100\% & 46,05 & 6,8 \\
\hline
\end{tabular}

Berdasarkan Tabel 3, perlakuan kombinasi pupuk hayati dan arang tempurung kelapa lebih baik pengaruhnya dalam meningkatkan hasil padi gogo dibandingkan perlakuan pupuk hayati atau arang tempurung kelapa saja. Perlakuan kombinasi pupuk hayati dan arang tempurung kelapa dapat meningkatkan hasil sebesar 30\% dibandingkan dengan kontrol. 
Hasil ini sejalan dengan Javaid (2011) bahwa aplikasi pupuk hijau sebagai amelioran organik dan pupuk hayati mampu meningkatkan hasil padi sampai dengan $46 \%$.

Pemupukan berbagai dosis N, P dan K pada padi gogo di tanah Ultisols tidak memberikan pengaruh yang nyata terhadap hasil tanaman padi gogo. Namun demikian, pemberian pupuk N, P, K 75\% yang diikuti oleh aplikasi pupuk hayati dan arang tempurung kelapa memberikan pengaruh hasil padi gogo yang lebih tinggi dengan peningkatan hasil sebesar 27,8\%. Dengan demikian aplikasi pupuk hayati dan arang tempurung kelapa dapat mengurangi kebutuhan pupuk anorganik sebesar 25\%.

\section{KESIMPULAN}

Berdasarkan hasil percobaan dapat disimpulkan bahwa tidak terdapat interaksi antara kombinasi pupuk hayati dan arang tempurung kelapa dengan dosis pupuk $\mathrm{N}, \mathrm{P}$, dan $\mathrm{K}$ terhadap pertumbuhan dan hasil padi gogo. Namun, aplikasi pupuk hayati dan tempurung kelapa berpotensi meningkatkan pertumbuhan dan hasil padi gogo. Perlakuan kombinasi pupuk hayati dan arang tempurung kelapa memberikan pengaruh terhadap jumlah anakan dan hasil padi gogo dengan peningkatan hasil sebesar 30\%.

Aplikasi berbagai dosis N, P, dan K pada padi gogo di tanah Ultisols tidak berpengaruh nyata terhadap pertumbuhan dan hasil tanaman padi gogo. Pemberian pupuk N, P, K 75\% yang diikuti oleh aplikasi pupuk hayati dan arang tempurung kelapa memberikan pengaruh hasil padi gogo.

\section{Ucapan Terimaksih}

Penelitian ini merupakan bagian dari Penelitian Terapan yang didanai oleh Kemenristek DIKTI tahun 2019. Terima kasih penulis sampaikan kepada staf Laboratorium Biologi Tanah Fakultas Pertanian Universitas Padjadjaran yang telah banyak membantu dalam produksi pupuk hayati.

\section{DAFTAR PUSTAKA}

Chaudhary. P., D. Jain, K. Anand, and D. Mitra. 2019. Biofertilizer: a sustainable approach for plant and soil health. In Mitra et. al. (Eds.). Microbial Resources for Sustainable Agriculture. LAP LAMBERT Academic Publishing. p: 106.

Sulistyani, E., D. B. Tamado, F. Wulandari, E. Budi. 2015. Coconut shell activated carbon as an alternative renewable energy. KnE Energy. 2: 76 - 81.

Fitriatin, B. N., R. Silpanus, E.T. Sofyan, A. Yuniarti, and T. Turmuktini. 2019. Effect of microbial fertilizers and dosage of NPK on growth and yield of upland rice (Oryza sativa L.). International Journal of Environment, Agriculture and Biotechnology. 4(4): 899-902.

Herlambang, S., P. B. Santoso, H. R. Sutiono and S. R. Nugraheni. 2020. The application of biochar and organic matter for proper cultivation on paddy soil. Journal of Degraded and Mining Lands Management. 7 (3): 2133-2137.

Husna, N., D. Budianta, Munandar, and A. Napoleon. 2019. Evaluation of several biochar types as inoculant carrier for indigenous phosphate solubilizing microoorganism from acid sulphate soil. Journal of Ecological Engineering. 20(6): 1-8.

Javaid, A. 2011. Effects of biofertilizers combined with different soil amendments on potted rice plants. Chilean Journal of Agricultural Research. 71(1):157-163

Khan, H. I. 2018. Appraisal of biofertilizers in rice: to supplement inorganic chemical fertilizer. Rice Science. 25(6): 357-362.

Mącik, M., A. Gryta and M. Frąc. 2020. Chapter two - biofertilizer in agriculture: an overview on concepts, strategies and effect on soil microorganisms. Advances of Agronomy. 162: 31-87.

Sudding and Jamaluddin. 2016. The processing of coconut shell based on pyrolysis technology to produce reneweable energy sources. Dalam Side, S. et. al. (Eds.). Proceedings of ICMSTEA International Conference on Mathematics, Science, Technology, 
Education, and their Applications. Makassar, 3 - 4 Oktober 2016. Hal: 498 510.

Wahane, M.R., N. A. Meshram, S. S. More and N. H. Khobragade. 2020. Biofertilizer and their role in sustainable agriculture-a review. The Pharma Innovation Journal. 9(7): 127-130.

Wasis, B., B. Winata and R. Andriani. 2018. Growth of Agathis dammara (Lamb. Rich.) seedling on gold tailing with addition of coconut shell charcoal and compost. Archives of Agriculture and Environmental Science. 3(2): 131-136. 